\title{
Effects of arsenate on the growth and microcystin production of Microcystis aeruginosa isolated from Taiwan as influenced by extracellular phosphate
}

\author{
Yan Gong • Hong-Nong Chou • Chi-dao Tu • Xi Liu • \\ Jiantong Liu • Lirong Song
}

Received: 12 November 2007 /Revised and accepted: 20 May 2008/Published online: 5 November 2008

(C) Springer Science + Business Media B.V. 2008

\begin{abstract}
Arsenic pollution and eutrophication are both prominent issues in the aquaculture ponds of Taiwan. It is important to study the effects of arsenic on algal growth and toxin production in order to assess the ecological risk of arsenic pollution, or at least to understand naturally occurring ponds. The sensitivity of algae to arsenate has often been linked to the structural similarities between arsenate and phosphate. Thus, in this study we examined the effects of arsenate $\left(10^{-8}\right.$ to $\left.10^{-4} \mathrm{M}\right)$ on Microcystis aeruginosa TY-1 isolated from Taiwan, under two phosphate regimes. The present study showed that $M$. aeruginosa TY-1 was arsenate tolerant up to $10^{-4} \mathrm{M}$, and that this tolerance was not affected by extracellular phosphate. However, it seems that extracellular phosphate contributed to microcystin production and leakage by $M$. aeruginosa in response to arsenate.
\end{abstract}

Y. Gong $\cdot$ X. Liu $\cdot$ J. Liu $(\bowtie) \cdot$ L. Song

Institute of Hydrobiology, Chinese Academy of Sciences,

Wuhan 430072, People's Republic of China

e-mail: jtliu@ihb.ac.cn

Y. Gong

Agricultural Testing and Information Center,

Hubei Academy of Agriculture Science,

Wuhan 430064, People's Republic of China

X. Liu

Graduate School of the Chinese Academy of Sciences,

Beijing 100039, People's Republic of China

H.-N. Chou

Institute of Fisheries Science, National Taiwan University,

Taipei 10617 Taiwan, China

C.-d. Tu

Department of Chemistry, National Central University,

Taoyuan 32001 Taiwan, China
Under normal phosphate conditions, total toxin yields after arsenate treatment followed a typical inverted U-shape hormesis, with a peak value of $2.25 \pm 0.06 \mathrm{mg} \mathrm{L}^{-1}$ in the presence of $10^{-7} \mathrm{M}$ arsenate, whereas $10^{-8}$ to $10^{-6} \mathrm{M}$ arsenate increased leakage of $\sim 75 \%$ microcystin. Under phosphate starvation, total toxin yields were not affected by arsenate, while $10^{-6}$ and $10^{-5} \mathrm{M}$ arsenate stimulated microcystin leakage. It is suggested that arsenate may play a role in the process of microcystin biosynthesis and excretion. Given the arsenic concentrations in aquaculture ponds in Taiwan, arsenate favors survival of toxic M. aeruginosa in such ponds, and arsenate-stimulated microcystin production and leakage may have an impact on the food chain.

Keywords Arsenate $\cdot$ Phosphate $\cdot$ Cyanobacterium . Microcystis aeruginosa $\cdot$ Microcystins

\section{Introduction}

Arsenic is ubiquitous in the environment and potentially toxic to humans (Smith et al. 2002). Its threat to the Western Pacific region has been noted (Suk et al. 2003). Of the various sources of arsenic in the environment, water-borne arsenic probably poses the greatest threat to human health. The spectrum of arsenic concentrations in natural waters ranges from 0.5 to $5,000 \mu \mathrm{g} \mathrm{L}^{-1}$ (about $6.7 \times 10^{-9}$ to $6.7 \times$ $10^{-5} \mathrm{M}$; Smedley and Kinniburgh 2002). Arsenic species comprise arsenate, arsenite, monomethylarsonic acid (MMAA), dimethylarsinic acid (DMAA), and other complex arseno-compounds such as arsenobetaine, arsenocholine and arsenosugars (Yukiko et al. 1996; Argese et al. 2005). Inorganic arsenic species can have a significant effect on the structure or physiology of phytoplankton communities (Knauer et al. 1999). Arsenate, the thermodynamically dominant 
species of arsenic in marine and estuarine surface waters, is taken up by the phosphate transport systems of phytoplankton and plants due to its structural similarity to phosphate (Smedley and Kinniburgh 2002; Manomita et al. 2004). Arsenate has been demonstrated in many cases to significantly reduce phosphate uptake in a competitive fashion (Wängberg and Blanck 1990; Bun-ya et al. 1996; Bleeker et al. 2003). Studies have indicated that the sensitivity of phytoplankton to arsenate may be species-specific (Planas and Healey 1978; Knauer et al. 1999); however, algal sensitivity to arsenate is related not only to the phosphate concentration in the culture medium (Planas and Healey 1978; Thiel 1988), but also to nutritional history (Creed et al. 1990).

Cyanobacterial blooms in freshwaters, especially cyanotoxins from some of the blooms, pose a major challenge for the supply of safe drinking water. Globally, the most common cyanotoxins are the cyclic peptide hepatoxins of the microcystin family, which are mainly from Microcystis blooms and can cause liver damage (Sivonen and Jones 1999). Like many other areas in the world, Microcystis blooms occur frequently in the eutrophic waters of Taiwan, especially in the aquaculture ponds used for eel, tilapia and carp (Lee et al. 1998). The groundwater used for aquaculture on the southwestern coast of Taiwan contains high concentrations of arsenic (Lin et al. 2004). It is not known whether arsenic has any relationship with cyanobacterial growth and toxin production in these aquaculture ponds. The water of culture ponds is dominated by arsenate (Huang et al. 2003). Therefore, our research, which investigated the effects of arsenate on Microcystis aeruginosa TY-1 isolated in Taiwan, under two phosphate regimes, was designed to answer the questions of whether extracellular phosphate protects cells from arsenate; and whether arsenate affects microcystin production and leakage under different phosphate regimes.

\section{Materials and methods}

Axenic cultures of unicellular M. aeruginosa TY-1 were isolated from Tauryuan, Taiwan (Lee et al. 1998). The strain was cultivated under a constant cool-fluorescent light intensity of $35 \mu \mathrm{mol}$ photons PAR $\mathrm{m}^{-2} \mathrm{~s}^{-1}, 16: 8 \mathrm{~h}$ light: day cycle and a temperature of $28 \pm 1^{\circ} \mathrm{C}$ in BG-11 medium. The cells in stationary phase were harvested by centrifugation and washed three times with sterile Milli-Q water $(18.0 \mathrm{~m} \Omega$ $\left.\mathrm{cm}^{-1}\right)$. Parts of the pellets were inoculated into $250 \mathrm{~mL}$ Erlenmeyer flasks in modified BG-11 medium, to which $\mathrm{PO}_{4}{ }^{3-}$ was added at $1.0 \mu \mathrm{M}$ for the phosphate-normal medium or omitted for the phosphate-starved medium. Arsenate, in the form of $\mathrm{Na}_{2} \mathrm{HAsO}_{4}$ was added to the culture medium at concentrations ranging from $10^{-8}$ to $10^{-4} \mathrm{M}$. The reason for the high concentrations of arsenate, such as $10^{-4} \mathrm{M}$, was to explore the inhibitory threshold dose of arsenate for growth of $M$. aeruginosa TY-1. The phosphate concentration used in this study $(1.0 \mu \mathrm{M})$ is similar to that under natural conditions according to United States Environmental Protection Agency standards (US EPA 1988). A culture in the same growth medium without addition of any arsenate was used as a control. Culture conditions for each treatment and the control were as described above, and all cultures were shaken at $100 \mathrm{rpm}$ to maintain cells in suspension. All samples were run in triplicate.

The stock bottles and culture flasks were soaked in $10 \%(\mathrm{v} / \mathrm{v})$ $\mathrm{HNO}_{3}$ for $12 \mathrm{~h}$, rinsed in Milli-Q water, dried overnight and sterilized prior to use. Culture media were autoclaved for a minimum of $30 \mathrm{~min}$ at $121^{\circ} \mathrm{C}$. Analytical reagent grade chemicals and Milli-Q water were used for preparation of all stock solutions and media.

Culture density was monitored by direct cell counts using a hemocytometer. Subsamples of $20 \mu \mathrm{L}$ were taken for the enumeration of cell density. All cultures were continued over the complete growth period. In the late exponential growth phase, samples of $1 \mathrm{~mL}$ were mixed with $9 \mathrm{~mL}$ acetone to achieve a final concentration of $90 \%$ acetone, extracted at $4{ }^{\circ} \mathrm{C}$ for $24 \mathrm{~h}$, and chlorophyll- $a$ was determined spectrophotometrically using specific absorption coefficients (Jeffrey and Humphrey 1975).

For analysis of microcystins using HPLC, a $30 \mathrm{~mL}$ subsample was harvested in the late exponential growth phase and filtered through a $\mathrm{CF} / \mathrm{C}$ glass fiber filter under low vacuum pressure $(0.1 \mathrm{MPa})$. Cells on the filters were preserved at $-20^{\circ} \mathrm{C}$ prior to microcystin analysis. For cell toxin analysis, samples were prepared and measured according to Ramanan et al. (2000). Toxins dissolved in the growth medium were concentrated and analyzed from $50 \mathrm{~mL}$ filtered supernatant according to Rivasseau et al. (1998).

For microcystins, each test solution was analyzed directly by HPLC with photodiode array ultraviolet detection (HPLCPDA-UV). Separation was accomplished under reverse-phase isocratic conditions with an octadecyl silica (ODS) column (Cosmosil 5C18-AR, 4.6×150 mm; Nacalai, Kyoto, Japan) and a mobile phase of $0.01 \mathrm{M}$ ammonium acetate: acetonitrile

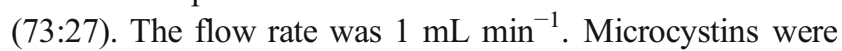
identified from their characteristic spectra. Quantification was carried out using peak areas of the test samples and comparing them with those of the standards available at $238 \mathrm{~nm}$. The microcystin (MC) standards (MC-LR, MC-RR and $\left.\left[\mathrm{Dha}^{7}\right] \mathrm{MC}-\mathrm{LR}\right)$ were obtained from Kanto Reagents (Tokyo, Japan). The liquid chromatography component consisted of a Hitachi (Tokyo, Japan) L-6200 pump and a Hitachi L-4200 UV-vis detector.

Statistical analysis was carried out with Microcal Origin (version 6.1, Microcal Software, Northampton, USA). Standard errors (SE) were calculated and Student's $t$ test was used to compare results obtained from the control and treatment cultures. The normality and homogeneity of variances were 
previously checked. In all statistical tests, a significance level of $5 \%$ was adopted.

\section{Results}

Figure 1 shows the effects of arsenate on the growth of Microcystis aeruginosa TY-1 at different phosphate concentrations. The growth patterns of $M$. aeruginosa at arsenate concentrations ranging from $10^{-8}$ to $10^{-4} \mathrm{M}$ were very similar to the control under phosphate-normal and phosphatestarved conditions (Fig. 1, $P>0.05$, two-sample paired $t$ test). The chlorophyll $a$ content of $M$. aeruginosa exposed to arsenate ranging from $10^{-8}$ to $10^{-4} \mathrm{M}$ also showed no difference from that of the control under both phosphate regimes (data not shown).

Microcystis aeruginosa TY-1 produced predominantly MC-LR and [ $\left.\mathrm{Dha}^{7}\right] \mathrm{MC}-\mathrm{LR}$. Compared with the control, intracellular MC-LR quotas of the phosphate-normal cells were inhibited by $32.2 \%$ and $44.8 \%$ in the presence of $10^{-5}$ and $10^{-4} \mathrm{M}$ arsenate, respectively (Fig. $2 \mathrm{a}, P<0.05$, twosample $t$ test). During phosphate-normal conditions, the extracellular MC-LR content was enhanced $\sim 45 \%$ with arsenate from $10^{-8}$ to $10^{-6} \mathrm{M}$ as compared to the control, whereas the extracellular $\left[\mathrm{Dha}^{7}\right] \mathrm{MC}-\mathrm{LR}$ content was stimulated by exposure to arsenate at concentrations from $10^{-8}$ to $10^{-5} \mathrm{M}$ (Fig. 2b, $P<0.05$, two-sample $t$ test). The phosphatestarved cells had an intracellular MC-LR quota approximately 1.4 times higher than that of the control when treated with $10^{-4} \mathrm{M}$ arsenate, while intracellular [Dha ${ }^{7} \mathrm{MC}-\mathrm{LR}$ content was not affected by arsenate (Fig. 2c, $P<0.04$, two-sample $t$ test). The highest extracellular MC-LR content of the toxic TY- 1 at $10^{-5} \mathrm{M}$ arsenate was an average of $61 \%$ higher than that of the control under phosphate starvation, but the extracellular $\left[\mathrm{Dha}^{7}\right] \mathrm{MC}-\mathrm{LR}$ content changed about two-fold when exposed to $10^{-5} \mathrm{M}$ arsenate (Fig. $2 \mathrm{~d}, P<0.05$, twosample $t$ test). In particular, the extracellular MC-LR content was only $\sim 14 \%$ of that of the control with $10^{-4} \mathrm{M}$ arsenate under both phosphate regimes (Fig. 2b,d).

Both the extra- and intra-cellular MC-LR contents were expressed as microgram per liter of cyanobacterial culture medium, and then the total toxin yield and ratio of extracellular microcystins to total toxins were calculated (Fig. 3). Under phosphate-normal conditions, total toxin yields after arsenate treatment followed an inverted U-shape pattern, with a peak value of $2.25 \pm 0.06 \mathrm{mg} \mathrm{L}^{-1}$ in the presence of $10^{-7} \mathrm{M}$ arsenate (Fig. 3a). The highest percentage in the growth medium was an average of $76.6 \%$ of total toxins in the presence of $10^{-6} \mathrm{M}$ arsenate under phosphate-normal conditions (Fig. 3b). Both the total toxin yield and the ratio of extracellular microcystins to total toxins increased with the concentration of arsenate in the range of $10^{-8}-10^{-6} \mathrm{M}$, and decreased at an arsenate concentration higher than $10^{-5} \mathrm{M}$. However, such a phenomenon was not observed during phosphate starvation. Total toxin yields were not affected by arsenate under phosphate starvation, but the ratio of extracellular microcystins to total toxins was stimulated by $10^{-6}$ and $10^{-5} \mathrm{M}$ arsenate as compared to the control $(P<0.05$, twosample $t$ test).

\section{Discussion}

Hardly any reports found in recent literature on the toxicity of arsenate to Microcystis consider the phosphate status of this cyanobacterium, although arsenate competition with phosphate has been reported for other phytoplankton species and organisms (Thiel 1988; Creed et al. 1990; Wängberg and

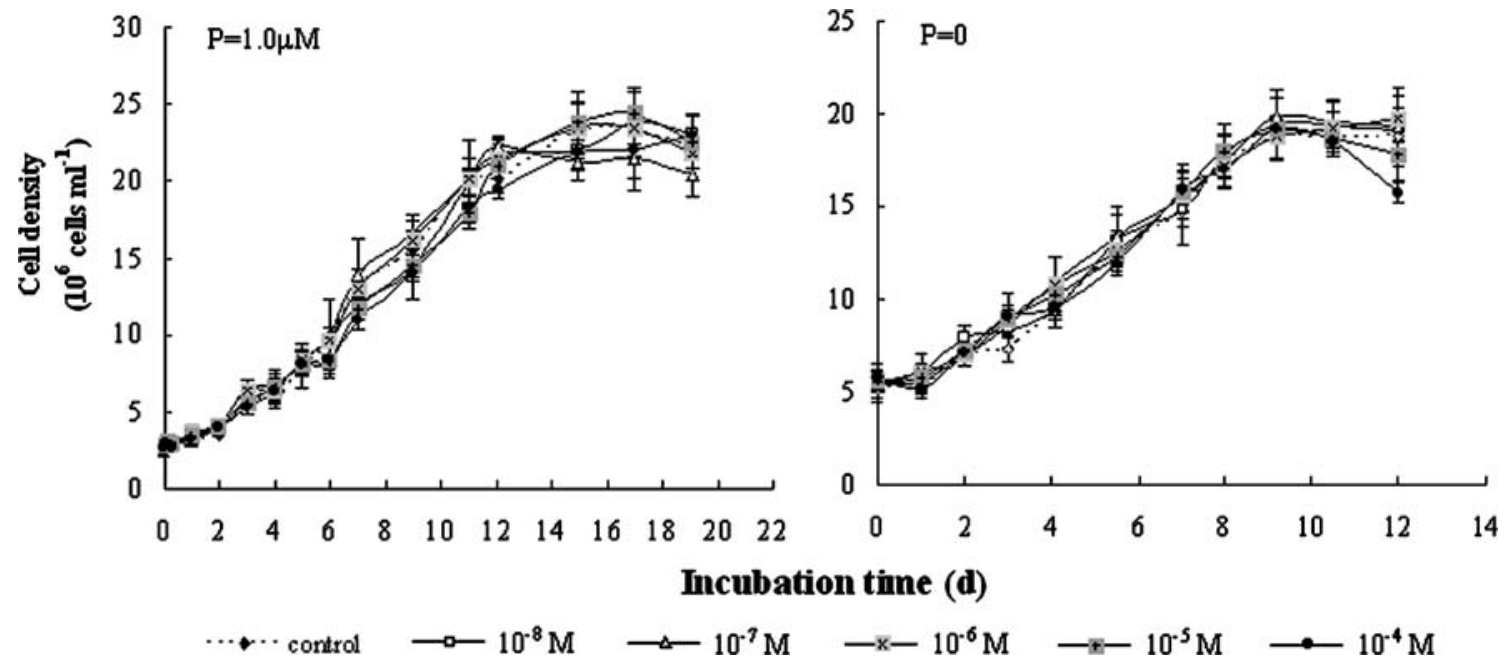

Fig. 1 Growth curves of Microcystis aeruginosa TY-1 exposed to various concentrations of arsenate under two phosphate regimes. Error bars Standard deviation $(n=3)$ 

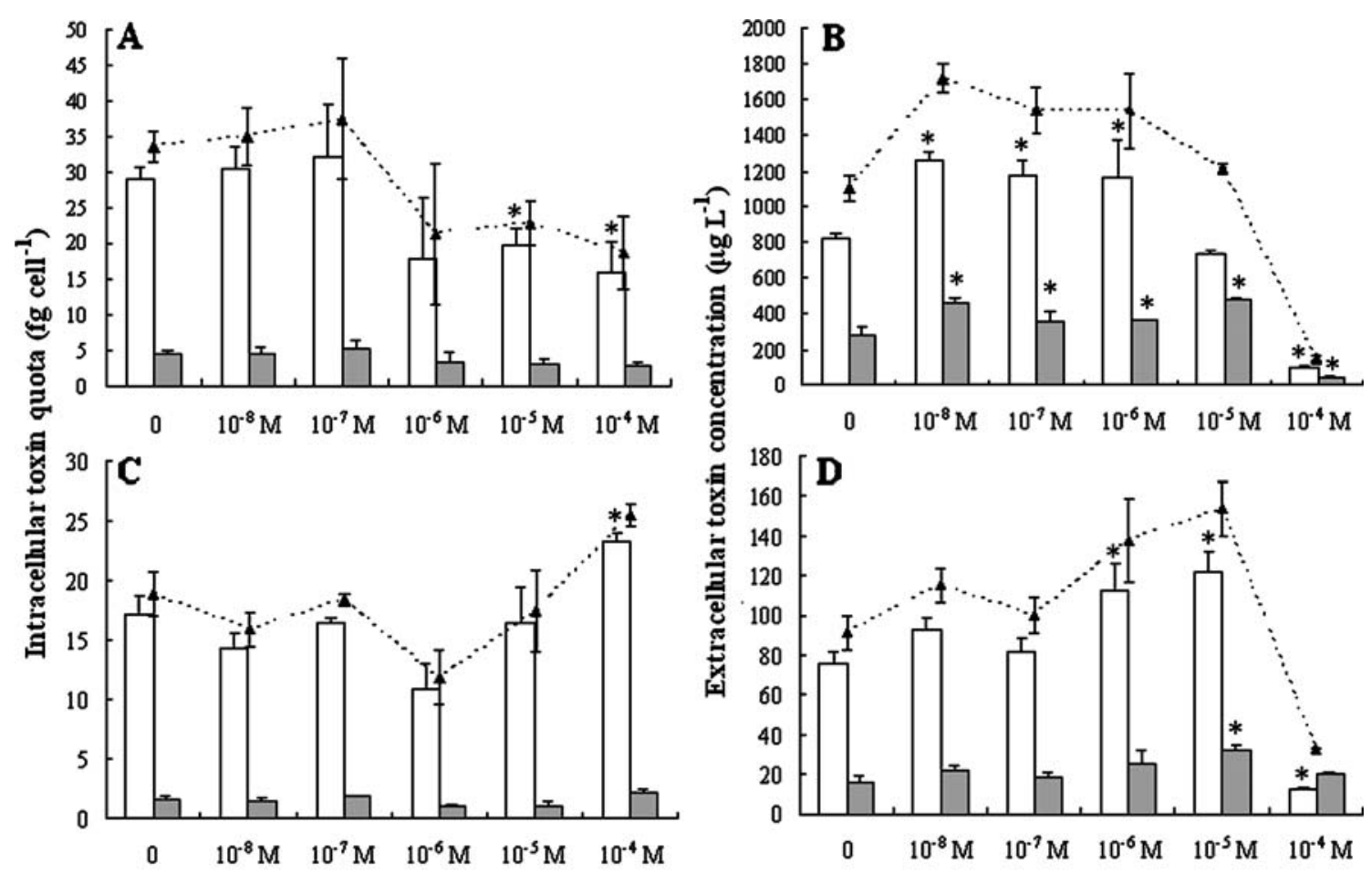

Arsenate content

Fig. 2 a-d Intra- and extra-cellular microcystin (MC)-LR levels (open bars), [Dha ${ }^{7}$ MC-LR levels (solid bars) and total MC levels (dotted line) of $M$. aeruginosa TY-1 exposed to various concentrations of arsenate under two phosphate regimes. a Intracellular MC quotas after 15 days exposure to phosphate-normal conditions; b extracellular MC content

Blanck 1990; Knauer and Hemond 2000). Growth is a good indicator of the action of noxious compounds in susceptible microorganisms, and reflects the metabolism of the cell (Blankley 1973). It was demonstrated that the arsenate/ phosphate ratio outside the cells did not directly govern the toxicity of arsenate, as shown by the growth curves of $M$. aeruginosa TY-1 (Fig. 1), which does not support the traditional view that phosphate-starved cells are more sensitive to arsenate (Thiel 1988; Wängberg and Blanck 1990). The tolerance of this Microcystis strain to arsenate was much greater than that of many freshwater microalgae, such as Chlamydocapsa cf. peterfii (Wängberg and Blanck 1990), Stichococcus bacillaris (Pawlik-Skowronska et al. 2004), and Monoraphidium arcuatum (Levy et al. 2005). The higher tolerance of $M$. aeruginosa TY-1 to arsenate may be the result of one (or a combination) of three alternatives. The first is that the high-affinity phosphate/arsenate uptake system may be suppressed by arsenate and was insensitive to cyanobacterial phosphorous status, as is the case in some arsenate-resistant plants (Meharg and Macnair 1992). The second explanation is that $M$. aeruginosa can detoxify arsenate via transfer to arsenite, and/or further to methylated arsenic species (Sanders 1979), and an arsenate reductase, pI258 ArsC, has been found in the cyanobacterium after 15 days exposure to phosphate-normal conditions; $\mathbf{c}$ intracellular MC quotas after 9 days exposure to phosphate-starved conditions; d extracellular MC content after 9 days exposure under phosphatestarved conditions. Error bars Standard deviation $(n=3)$, *significant difference from the control $(P<0.05)$

Synechocystis sp. PCC6803 (Li et al. 2003). A mathematical model has been constructed to simulate arsenate transformation in algae under P-limited and P-non-limited conditions (Hellweger et al. 2003). The third explanation is that high intracellular concentrations of phosphorus reduce the possibility of arsenate successfully competing with phosphate for enzymatic sites (Meharg 1994), since M. aeruginosa is capable of luxury uptake and accumulation of phosphate in several-fold excess of demand when exposed to considerable amounts of phosphate in BG-11 medium prior to arsenate exposure (Jacobson and Halmann 1982; Baldia et al. 2007).

Microcystis with hepatotoxicity, which can cause liver damage or even liver haemorrhage, is a common bloomforming cyanobacterium in eutrophic freshwaters world wide (Sivonen and Jones 1999). At least 76 different microcystin analogs have been found in natural blooms and laboratory cultures of cyanobacteria (Acero et al. 2005). In particular, MC-RR, LR and [Dha $\left.{ }^{7}\right] \mathrm{MC}-\mathrm{LR}$ are commonly found in freshwater cyanobacterial blooms in China (Chen et al. 2006). Microcystis aeruginosa TY-1 isolated from Taiwan produces two main microcystins, MC-LR and [Dha $\left.{ }^{7}\right] \mathrm{MC}-$ LR. MC-LR is the most common variant of all the microcystins, and also the most toxic, with an $\mathrm{LD}_{50}$ of $50 \mu \mathrm{g} \mathrm{kg}^{-1}$ (Dawson 1998), whereas the toxicity of [Dha $\left.{ }^{7}\right] \mathrm{MC}-\mathrm{LR}$ is 


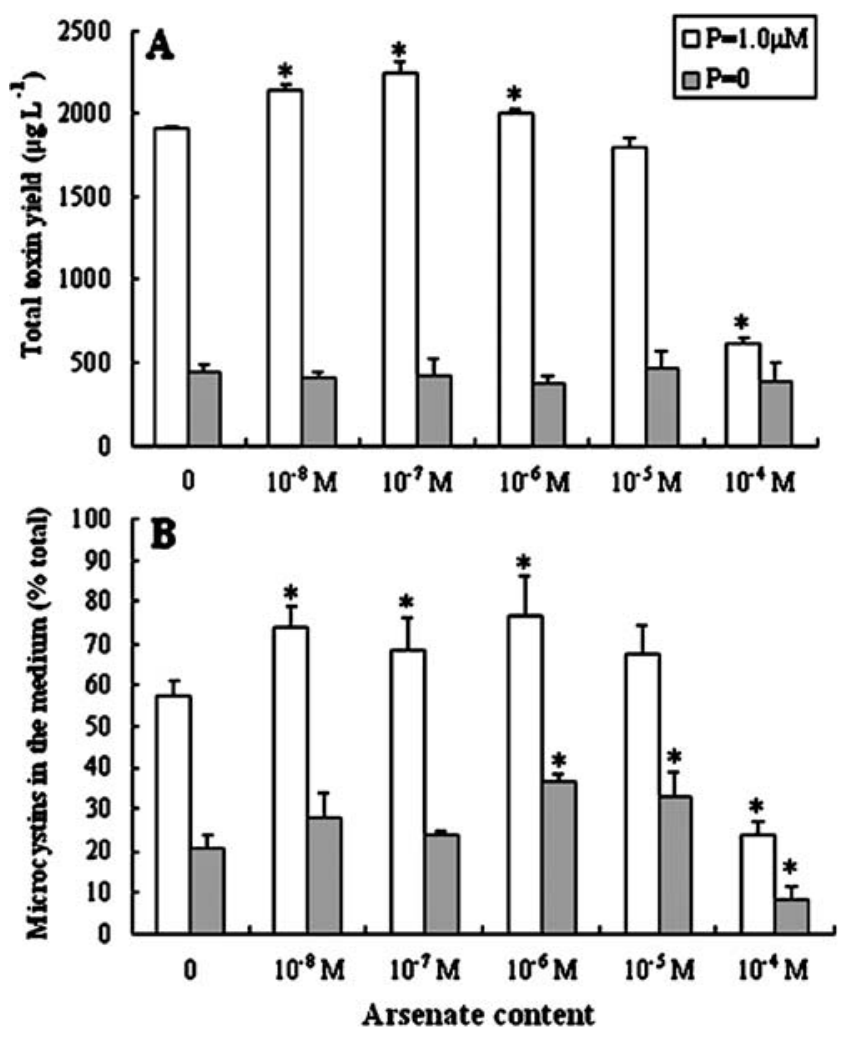

Fig. 3 Total toxin content (a) and the ratio of extracellular microcystins to total toxin content (b) for M. aeruginosa TY-1 exposed to various concentrations of arsenate under two phosphate regimes. Error bars Standard deviation $(n=3),{ }^{*}$ significant difference from the control $(P<0.05)$

about one-fifth of that of MC-LR (Sivonen and Jones 1999). Thus, it was important to analyze the microcystin composition resulting from exposure to arsenate. Our results showed that toxicity was related mainly to the intracellular level of MC-LR, which was the only microcystin type altered by arsenate under both phosphate regimes. However, variation in the toxicity of the culture medium was directly correlated with changes in both extracellular microcystin levels when the cyanobacterium was exposed to arsenate.

Microcystins are considered as being primary intracellular, and microcystin leakage is generally considered to be linked to a decrease in cell integrity (White et al. 2005). However, in M. aeruginosa TY-1, microcystins are released during the log phase of growth and accumulate continuously in the medium, and extracellular microcystins contribute up to $\sim 60 \%$ of total toxin yields in the late exponential growth phase when this strain is cultivated in medium containing $0.3 \mathrm{mM} \mathrm{PO}_{4}{ }^{3-}$ (Lin 2007). It was also observed in this study that $57.6 \pm 3.7 \%$ of total microcystins of Microcystis TY-1 without arsenate exposure leaked into the culture medium under phosphate-normal conditions $\left(1.0 \mu \mathrm{M} \mathrm{PO}_{4}{ }^{3-}\right)$. However, only $20.7 \pm 3.0 \%$ of the total microcystin yield was released under phosphate starvation without arsenate expo- sure. On the other hand, extracellular phosphate did not affect microcystin leakage in Microcystis PCC7806 under phosphate starvation (Gong et al. 2008). It is worth mentioning that Microcystis PCC7806 stores most microcystins in cells, and only $4 \%$ of the total toxin amount is found outside the cells in late exponential growth phase (Rivasseau et al. 1998). A single amino acid difference in the $m c y \mathrm{H}$ sequence has been found in Microcystis TY-1 in comparison with Microcystis PCC7806 (Lin 2007). The sequence of $m c y \mathrm{H}$ is known to be homologous to the bacterial $\mathrm{ABC}$ transporter, but it is also known as a key protein that maintains the integrity of microcystin synthetase clusters (Pearson et al. 2004). Microcystis TY-1 is suggested to have the inherent ability of microcystin excretion. Phosphate has been shown to support the necessary enzymes, precursors and energy charge for microcystin synthesis (Dai et al. 2008). Threfore, it is hypthesised that phosphate can inhibit microcystin production and leakage when it is the limiting factor for cells (Fig. 3). Meanwhile, as Microcystis PCC7806 does not possess the ability to excrete microcystin, extracellular phosphate would not affect the leakage of microcystins, but could have a similar effect on total microcystin yields as for Microcystis TY-1 (Gong et al. 2008).

The present study has shown that arsenate has some effect on the dissolved microcystin level under both phosphate regimes. The cyanobacterial cells were expected to produce more extracellular microcystins due to induction of the transcription of $m c y$ genes when exposed to low doses of arsenate, since both total microcystin yields and microcystin excretion increased with $10^{-8}-10^{-6} \mathrm{M}$ arsenate under phosphate-normal conditions. The most likely reason for microcystin production in cyanobacteria is defence against grazers (Rohrlack et al. 1999). It is presumed that the defence capability of Microcystis cells is enhanced by exposure to arsenate provided as a competitor of phosphate. However, it is not clear that total microcystin yields were invariable with arsenate exposure under phosphate starvation, while microcystin excretion was variable. Intracellular phosphate/arsenate perhaps does not play a role in microcystin production but rather affects the release of microcystin from cells under phosphate starvation. Further experiments are needed to study the expression levels of the toxin and transporter genes to clarify the above problems.

The response to arsenate of total microcystin production in this $M$. aeruginosa strain under phosphate-normal conditions seemed to be an inverted U-shaped hormesis, as described by Stebbing (1982), which varied from being enhanced at lower doses to being decreased (due to toxicity) at higher doses. The peak values measured here were $\sim 120 \%$ of control values when treated with $10^{-7} \mathrm{M}$ arsenate, which is within the range of typical hormetic responses proposed by Calabrese and Baldwin (1997). Based on a recent report on the range of arsenic levels of aquaculture ponds in Taiwan $\left(1.92 \times 10^{-7}\right.$ 
$2.95 \times 10^{-6} \mathrm{M}$ ) and the predominance of arsenate in the water (Huang et al. 2003), it is likely that $M$. aeruginosa TY-1 could grow well, in addition to producing and excreting more microcystins in arsenic-polluted ponds with the coexistence of phosphate. The bioaccumulation of microcystins by fish has been reviewed by Ibelings and Chorus (2007). This implies that risks to human health might be increased through consumption of fish harvested from culture ponds containing arsenate and toxic Microcystis.

In summary, this is the first report on the effects of arsenate on the growth and microcystin production of $M$. aeruginosa isolated from Taiwan under different phosphate regimes. The traditional view that phosphate-starved cells were necessarily more sensitive to arsenate toxicity may not be correct. Our study suggests that $M$. aeruginosa TY-1 is tolerant to arsenate, and this tolerance is not affected by extracellular phosphate content. The stimulation of microcystin production in $M$. aeruginosa TY-1 at low concentration of arsenate $\left(10^{-8}-10^{-6} \mathrm{M}\right)$ under normal phosphate conditions might be an effect of hormesis. It is speculated that arsenate may play a role in the process of microcystin biosynthesis and excretion, yet this remains to be verified. Given the known arsenic concentrations in aquaculture ponds of Taiwan, it is likely that arsenate favors survival of toxic M. aeruginosa in the ponds; it is evident that low doses of arsenate stimulate microcystin production and leakage, which may increase the risk of human exposure to hepatotoxins through the food chain.

Acknowledgment The study was supported by the State Key Basic Research and Development Plan (973 Plan, Grant No. 2002CB412304).

\section{References}

Acero JL, Rodriguez E, Meriluoto J (2005) Kinetics of reactions between chlorine and the cyanobacterial toxins microcystins. Water Res 39:1628-1638 doi:10.1016/j.watres.2005.01.022

Argese E, Bettiol C, Rigo C, Bertini S, Colomban S, Ghetti PF (2005) Distribution of arsenic compounds in Mytilus galloprovincialis of the Venice Lagoon (Italy). Sci Total Environ 348:267-277 doi:10.1016/j.scitotenv.2004.12.071

Baldia SF, Evangelista AD, Aralar EV, Santiago AE (2007) Nitrogen and phosphorus utilization in the cyanobacterium Microcystis aeruginosa isolated from Laguna de Bay, Philippines. J Appl Phycol 19:607-613 doi:10.1007/s10811-007-9209-0

Blankley WF (1973) Toxic and inhibitory materials associated with culturing. In: Stein JR (ed) Handbook of phycological methods. Cambridge University Press, Cambridge, pp 207-223

Bleeker PM, Schat H, Vooijs R, Verkleij JAC, Ernst WHO (2003) Mechanisms of arsenate tolerance in Cytisus striatus. New Phytol 157:33-38 doi:10.1046/j.1469-8137.2003.00542.x

Bun-ya M, Shikata K, Nakade S, Yompakdee C, Harashima S, Oshima Y (1996) Two new genes, PHO86 and PHO87, involved in inorganic phosphate uptake in Saccharomyces cerevisiae. Curr Genet 29:344-351
Calabrese EJ, Baldwin LA (1997) A quantitatively-based methodology for the evaluation of chemical hormesis. Hum Ecol Risk Assess 3:545-554

Chen W, Song L, Gan N, Li L (2006) Sorption, degradation and mobility of microcystins in Chinese agriculture soils: risk assessment for groundwater protection. Environ Pollut 144:752-758 doi:10.1016/j. envpol.2006.02.023

Creed IF, Havas M, Trick CG (1990) Effects of arsenate on growth of nitrogen- and phosphate-limited Chlorella vulgaris (Chlorophyceae) isolates. J Phycol 26:641-650 doi:10.1111/j.0022-3646.1990. 00641.x

Dai R, Liu H, Qu J, Zhao X, Ru J, Hou Y (2008) Relationship of energy charge and toxin content of Microcystis aeruginosa in nitrogen-limited or phosphorous-limited cultures. Toxicon 51:649-658 doi:10.1016/j.toxicon.2007.11.021

Dawson RM (1998) The toxicology of microcystins. Toxicon 36:953962 doi:10.1016/S0041-0101(97)00102-5

Gong Y, Song L, Wu X, Xiao B, Fang T, Liu J (2008) Effects of arsenate on microcystin content and leakage of Microcystis strain PCC7806 under various phosphate regimes. Environ Toxicol (in press)

Hellweger FL, Farley KJ, Lall U, Toro DMD (2003) Greedy algae reduce arsenate. Limnol Oceanogr 48:2275-2288

Huang Y-K, Lin K-H, Chen H-W, Chang C-C, Liu C-W, Yang M-H et al (2003) Arsenic species contents at aquaculture farm and in farmed mouthbreeder (Oreochromis mossambicus) in blackfoot disease hyperendemic areas. Food Chem Toxicol 41:1491-1500 doi:10.1016/S0278-6915(03)00165-0

Ibelings BW, Chorus I (2007) Accumulation of cyanobacterial toxins in freshwater "seafood" and its consequences for public health: a review. Environ Pollut 150:177-192 doi:10.1016/j.envpol.2007.04.012

Jacobson L, Halmann M (1982) Polyphosphate metabolism in the blue-green alga Microcystis aeruginosa. J Plankton Res 4:481488 doi:10.1093/plankt/4.3.481

Jeffrey SW, Humphrey GF (1975) New spectrophotometric equations for determining chlorophyll $a, b, c 1$ and $c 2$ in high plants, algae and natural phytoplankton. Biochem Physiol Pflanz 167:191-194

Knauer K, Hemond H (2000) Accumulation and reduction of arsenate by the freshwater green alga Chlorella sp. (Chlorophyta). J Phycol 36:506-509 doi:10.1046/j.1529-8817.2000.99056.x

Knauer K, Behra R, Hemond H (1999) Toxicity of inorganic and methylated arsenic to algal communities from lakes along an arsenic contamination gradient. Aquat Toxicol 46:221-230 doi:10.1016/ S0166-445X(98)00131-3

Lee T-H, Chen Y-M, Chou H-N (1998) First report of microcystins in Taiwan. Toxicon 36:247-255 doi:10.1016/S0041-0101(97)00128-1

Levy JL, Stauber JL, Adams MS, Maher WA, Kirby JK, Jolley DF (2005) Toxicity, biotransformation, and mode of action of arsenic in two freshwater microalgae (Chlorella $\mathrm{sp}$. and Monoraphidium arcuatum). Environ Toxicol Chem 24:2630-2639 doi:10.1897/ 04-580R.1

Li R, Haile JD, Kennelly PJ (2003) An arsenate reductase from Synechocystis sp. strain PCC 6803 exhibits a novel combination of catalytic characteristics. J Bacteriol 185:6780-6789 doi:10.1128/ JB.185.23.6780-6789.2003

Lin J-Z (2007) Concerns of the application of $m c y$ genes analysis in the toxic Microcystis population screening and observations on the release of microcystins. Masters thesis, National Taiwan University.

Lin MC, Cheng HH, Lin HY, Chen YC, Chen YP, Liao CM et al (2004) Arsenic accumulation and acute toxicity in milkfish (Chanos chanos) from blackfoot disease area in Taiwan. Bull Environ Contam Toxicol 72:248-254 doi:10.1007/s00128-003-9041-4

Manomita PM, Bhowmik N, Bandopadhyay B, Sharma A (2004) Comparison of mercury, lead and arsenic with respect to genotoxic effects on plant systems and the development of genetic tolerance. 
Environ Exp Bot 52:199-223 doi:10.1016/j.envexpbot.2004. 02.009

Meharg AA (1994) Integrated tolerance mechanisms: constitutive and adaptive plant responses to elevated metal concentrations in the environment. Plant Cell Environ 17:989-993 doi:10.1111/j.13653040.1994.tb02032.x

Meharg AA, Macnair MR (1992) Suppression of the high-affinity phosphate-uptake system-a mechanism of arsenate tolerance in Holcus lanatus L. J Exp Bot 43:519-524 doi:10.1093/jxb/43.4.519

Pawlik-Skowronska B, Pirszel J, Kalinowska R, Skowronski T (2004) Arsenic availability, toxicity and direct role of GSH and phytochelatins in As detoxification in the green alga Stichococcus bacillaris. Aquat Toxicol 70:201-212 doi:10.1016/j.aquatox.2004.09.003

Pearson LA, Hisbergues M, Borner T, Dittmann E, Neilan BA (2004) Inactivation of an $\mathrm{ABC}$ transporter gene, $m c y \mathrm{H}$, results in loss of microcystin production in the cyanobacterium Microcystis aeruginosa PCC 7806. Appl Environ Microbiol 70:6370-6378 doi:10.1128/AEM.70.11.6370-6378.2004

Planas D, Healey FP (1978) Effects of arsenate on growth and phosphate metabolism of phytoplankton. J Phycol 14:337-341 doi:10.1111/j.1529-8817.1978.tb00309.x

Ramanan S, Tang J, Velayudhan A (2000) Isolation and preparative purification of microcystin variants. J Chromatogr A 833:103112 doi:10.1016/S0021-9673(00)00378-2

Rivasseau C, Martins S, Hennion M-C (1998) Determination of some physicochemical parameters of microcystins (cyanobacterial toxins) and trace level analysis in environmental samples using liquid chromatography. J Chromatogr A 799:155-169 doi:10.1016/S00219673(97)01095-9

Rohrlack T, Dittmann E, Henning M, Börner T, Kohl J-G (1999) Role of microcystins in poisoning and food ingestion inhibition of Daphnia galeata caused by the cyanobacterium Microcystis aeruginosa. Appl Environ Microbiol 65:737-739

Sanders JG (1979) Effects of arsenic speciation and phosphate concentration on arsenic inhibition of Skeletonema costatum (Bacillariophyceae). J Phycol 15:424-428
Sivonen K, Jones G (1999) Cyanobacterial toxins. In: Chorus I, Bartram J (eds) Toxic cyanobacteria in water: a guide to their public health consequences, monitoring and management. World Health Organization, London, pp 73-82

Smedley PL, Kinniburgh DG (2002) A review of the source, behavior and distribution of arsenic in natural waters. Appl Geochem 17:517-568 doi:10.1016/S0883-2927(02)00018-5

Smith AH, Lopipero PA, Bates MN, Steinmaus CM (2002) Arsenic epidemiology and drinking water standards. Science 296:21452146 doi: $10.1126 /$ science. 1072896

Stebbing ARD (1982) Hormesis: the stimulation of growth by low levels of inhibitors. Sci Total Environ 22:213-234 doi:10.1016/ 0048-9697(82)90066-3

Suk WA, Ruchirawat KM, Balakrishnan K, Berger M, Carpenter D, Damstra T et al (2003) Environmental threats to children's health in Southeast Asia and the Western Pacific. Environ Health Perspect 111:1340-1347

Thiel T (1988) Phosphate transport and arsenate resistance in the cyanobacterium Anabaena variabilis. J Bacteriol 170:1143-1147

US EPA (1988) Quality criteria for water (US EPA 440/5-86-001). Office of Water Regulations and Standards. US Government Printing Office (PB81-226759). Washington, DC

Wängberg S-A, Blanck H (1990) Arsenate sensitivity in marine periphyton communities established under various nutrient regimes. J Exp Mar Biol Ecol 139:119-134 doi:10.1016/0022-0981(90) 90042-B

White SH, Duivenvoorden LJ, Fabbro LD (2005) A decision-making framework for ecological impacts associated with the accumulation of cyanotoxins (cylindrospermopsin and microcystin). Lake Reservior Manage 10:25-37 doi:10.1111/j.1440-1770.2005. 00258.x

Yukiko OO, Kaise T, Ochi T (1996) Induction of chromosomal aberrations in cultured human fibroblasts by inorganic and organic arsenic compounds and the different roles of glutathione in such induction. Mutat Res 357:123-129. doi:10.1016/0027-5107(96) 00092-9 